\title{
Effect of Sterile Cytoplasms on Content of Absolutely Dry Matter in the Grain Sorghum Hybrids
}

\author{
Bychkova Vera ${ }^{1}$, Elkonin Lev ${ }^{2, *}$ \\ ${ }^{1}$ Russian Research, Design and Technology Institute of Sorghum and Maize, Saratov, Russia. \\ ${ }^{2}$ Federal Agrarian Research Centre of South-East Region, Saratov, Russia.
}

How to cite this paper: Bychkova Vera, Elkonin Lev. (2021) Effect of Sterile Cytoplasms on Content of Absolutely Dry Matter in the Grain Sorghum Hybrids. International Journal of Food Science and Agriculture, 5(4), 601-607.

DOI: 10.26855/ijfsa.2021.12.006

Received: September 10, 2021

Accepted: October 6, 2021

Published: October 22, 2021

"Corresponding author: Elkonin Lev, Federal Agrarian Research Centre of South-East Region, Saratov, Russia. Email: lelkonin@gmail.com

\begin{abstract}
Analysis of the content of absolutely dry matter (ADM) is one of the main indicators of the productivity of varieties and hybrids in crop plants. In this study, we investigated the effect of the type of sterile cytoplasm on the content of ADM in the $\mathrm{F}_{1}$ hybrids of grain sorghum obtained on the basis of two series of alloplasmic iso-nuclear CMS-lines-with genomes of the Zheltozernoe 10 (in A3, A4, and 9E cytoplasms) and Pischevoe 614 (in 9E and M35-1A cytoplasms). The varieties of grain sorghum Mercury and Pischevoe 35 were used as pollen parents. The studies were carried out at the stages of "emergence - tillering", "tillering - heading" and "heading - complete maturity" for three years with different hydrothermal conditions. For the first time, the effect of the type of sterile cytoplasm on the content of ADM and the manifestation of true heterosis for this trait was shown. In each season, the A3 cytoplasm significantly reduced the ADM content in the $F_{1}$ hybrids with both pollen parents at the "tillering - heading" stage, whereas the 9E cytoplasm increased the ADM content at the "heading - complete maturity" stage. The manifestation of cytoplasmic effects depended on the hydrothermal regime of plant growing: the most significant differences between the hybrids in different types of sterile cytoplasms were observed under drought conditions, the 9E cytoplasm increased, and the A3 cytoplasm decreased the ADM content, whereas in the seasons with mild conditions these differences were less pronounced. The data obtained indicate the genetic influence of the cytoplasm on the assimilation capacity of sorghum hybrids and tolerance to drought stress.
\end{abstract}

\section{Keywords}

Absolutely dry matter, Cytoplasmic male sterility, Drought tolerance, $F_{1}$ hybrids, Heterosis, Sorghum bicolor (L.) Moench

\section{Introduction}

Drought is one of the key factors affecting crop productivity. In the regions prone to drought, one of the main problems of plant production is the use of varieties and hybrids capable of producing high yield potential in conditions of moisture deficiency. Grain sorghum [Sorghum bicolor (L.) Moench] compares favorably with other cereals, since many varieties and hybrids of this crop have a number of physiological mechanisms that provide high drought tolerance such as osmotic adjustments, leaf rolling, waxyness on stem, root architecture, transpiration efficiency,stay green [1-4]. Sorghum grain is a dietary staple for many million people in more than 30 countries. In addition, sorghum grain does not contain gluten and can serve as a source of protein for people suffering from celiac disease and gluten intolerance [5]. 
$\mathrm{F}_{1}$ hybrids play a significant role in the sorghum production, since they surpass the parental lines in grain and green mass yield by $15-30$, and sometimes by $50 \%$ [6-8]. The commercial production of hybrid seeds in sorghum is impossible without the use of lines with cytoplasmic male sterility (CMS). For this purpose, in sorghum for a long time, the only type of CMS (A1) was used, which is based on the milo cytoplasm type. Later, as a result of hybridization of cultivars and accessions belonging to different races of the genus Sorghum, new types of CMS were identified [9]. Currently, more than 10 different types of CMS in sorghum were found [10,11]. These cytoplasms differ by mechanisms and genetic control of fertility restoration, morphology and histological structure of anthers, stages of pollen degeneration, structure of mitochondrial and chloroplast genomes. The use of genetically different types of sterile cytoplasms significantly increases the diversity of CMS lines, and thereby expands the range of hybrid combinations, which contributes to the creation of new commercial $\mathrm{F}_{1}$ hybrids with a heterosis effect.

It is well known that the mitochondrial genome, through retrograde regulation, can influence the expression of numerous nuclear genes that control diverse plant traits, including the resistance to environmental stresses [12-15]. In this regard, the use of genetically different types of CMS in sorghum breeding necessitates detailed investigation of the effects of sterile cytoplasms on the manifestation of various traits of sorghum plants, including those of great biological and economic importance. Among such traits is the content of absolutely dry matter (ADM) that characterizes the assimilation capacity and nutritional value of cultivars and hybrids. ADM includes a variety of substances that accumulate during ontogenesis as a result of various metabolic processes (protein, fat, fiber, phosphorus, calcium, nitrogen-free extractives, etc.) [16]. It is due to high ADM content sorghum is an important forage crop for drought- prone regions [17].

The aim of this work was to study the effect of different types of sterile cytoplasms (A3, A4, 9E, M35-1A) on the content of absolutely dry matter and the manifestation of true heterosis for this trait in $\mathrm{F}_{1}$ hybrids of grain sorghum.

\section{Methods}

The $\mathrm{F}_{1}$ grain sorghum [Sorghum bicolor (L.) Moench] hybrids obtained on the basis of two series of iso-nuclear CMS lines were used in this study. The first series had the nuclear genome of the fertile line Zheltozernoe 10 (Zh10) transferred into CMS-inducing cytoplasms A3 (IS1112C), A4 (IS7920C) and 9E (IS17218) [18]. The second series had the nuclear genome of the fertile line Pishchevoe 614 (P614) transferred into CMS-inducing cytoplasms 9E and M35-1A. These lines were obtained by consecutive backcrosses of the corresponding fertile lines with CMS lines A3 Tx398, A4 Tx398, 9E Tx398 and Indian line M35-1A (provided by Dr. K. F. Schertz, Texas Agricultural Experimental Station, USA). In this study, maternal lines with Zh10 nuclear genome passed 15 consecutive backcrosses, and maternal lines with P614 nuclear genome passed 9 consecutive backcrosses. Mercury and Pishchevoe 35 varieties of grain sorghum were used as paternal lines for studied hybrids.

Parental lines and $F_{1}$ hybrids were grown in the experimental field of the Federal State Budgetary Scientific Institution "Rossorgo" (Saratov, Russia). Sowing was carried out with a row spacing of $70 \mathrm{~cm}$. Plot area was $7.7 \mathrm{~m}^{2}$. The planting density was 80 thousand plants/ha. The placement of the plots was randomized, in three replications [19].

ADM was determined at the stages of "emergence - tillering", "tillering - heading" and "heading - full maturity". The duration of the interphase period "emergence - full maturity" was 88-115 days in 2010, 102-120 days in 2012 and 99-106 days in the 2013 season. For ADM yield accounting, the samples were taken from $1 \mathrm{~m}^{2}$. Stems, leaves, and panicles from each sample were dried separately in an oven at $105^{\circ} \mathrm{C}$ for 48 hours until constant weight. Moisture was determined as the ratio between the wet weight and dry weight. The ADM yield was expressed as t/ha.

Two-way variance analysis with the Duncan's Multiple Range Test was used to study the difference between the studied hybrids. Calculations were performed using the AGROS 2.09 software (S.P. Martynov, Institute of General Genetics, Russian Academy of Science).

Manifestation of true heterosis $(\mathrm{H})$ for ADM, or heterobelteosis, superiority over the best parent, was calculated according to the formula [20]:

$$
H=\frac{F 1-B P}{B P} \cdot 100 \%
$$

where $F_{1}=$ value of $F_{1}, B P=$ value of better parent.

The studies were carried out for three years (2010, 2012 and 2013), which were characterized by contrasting meteorological conditions: 2010 was characterized by extremely high temperatures throughout the entire plant ontogenesis and a sharp deficit of precipitation. The average monthly temperature in 2010 was $17.9^{\circ}, 24.4^{\circ}, 27.9^{\circ}$ and $26.5^{\circ} \mathrm{C}$ (in May, June, July and August, respectively), in $2012-19.2^{\circ}, 22.6^{\circ}, 23.7^{\circ}$ and $22.4^{\circ} \mathrm{C}$, and in $2013-19.6^{\circ}, 20.9^{\circ}, 21.4^{\circ}$ and $21.7^{\circ} \mathrm{C}$. The total precipitation for the growing season in 2010 was $38.8 \mathrm{~mm}$, in $2012-145.8 \mathrm{~mm}, 2013-110 \mathrm{~mm}$. In 2012, the second half of the growing season was characterized by an excess of precipitation, and in 2013, the first half of the growing season had excess of precipitation.

To study the effect of hydrothermal regime of plant cultivation on the influence of sterile cytoplasms on the ADM 
accumulation, the hydrothermal coefficient (HTC) was calculated. HTC was determined by the ratio of precipitation during the growing season to the sum of temperatures for the same period, reduced by 10 times [21]. HTC for the entire growing season in 2010 was 0.15-0.18 (severe drought); in 2012, 0.69-0.72 (moderately dry-insufficiently humid) and in 2013 0.99-1.12 (insufficiently humid-sufficiently humid).

\section{Results}

Analysis of ADM indices in the hybrids with the iso-nuclear CMS-lines with Zh10 nuclear genome in the A3, A4, and 9E cytoplasms showed that, on average, over 3 years, significant differences were observed at the "tillering - heading" stage. The A3 cytoplasm significantly reduced the indices of ADM in hybrids with both pollinators (Table 1). At the "heading - full maturity" stage, significant differences over 3 years were observed in hybrids with Mercury, the 9E cytoplasm had the highest index, which was 11.41 t/ha (Table 1). No significant differences were found at this stage in hybrids with Pishchevoe 35; however, on average, for both hybrid combinations, cytoplasm 9E also significantly increased the ADM indicators.

It is noteworthy that the strongest differences between hybrids with Mercury in different types of sterile cytoplasms were observed at all stages of ontogenesis in arid 2010 with low HTC value, the 9E cytoplasm increased, and the A3 cytoplasm decreased the ADM value, while in other years with higher HTC these differences were less clear (Table 1). Similar results were observed in hybrids with Pishchevoe 35. The significance of cytoplasm $\times$ year interaction was confirmed by variance analysis (Table 1).

Table 1. Content of the absolutely dry matter in $\mathrm{F}_{1}$ grain sorghum hybrids obtained on the basis of iso-nuclear $\mathrm{CMS}$-lines with Zh10 nuclear genome in the A3, A4, and 9E cytoplasm, t/ha, 2010-2013

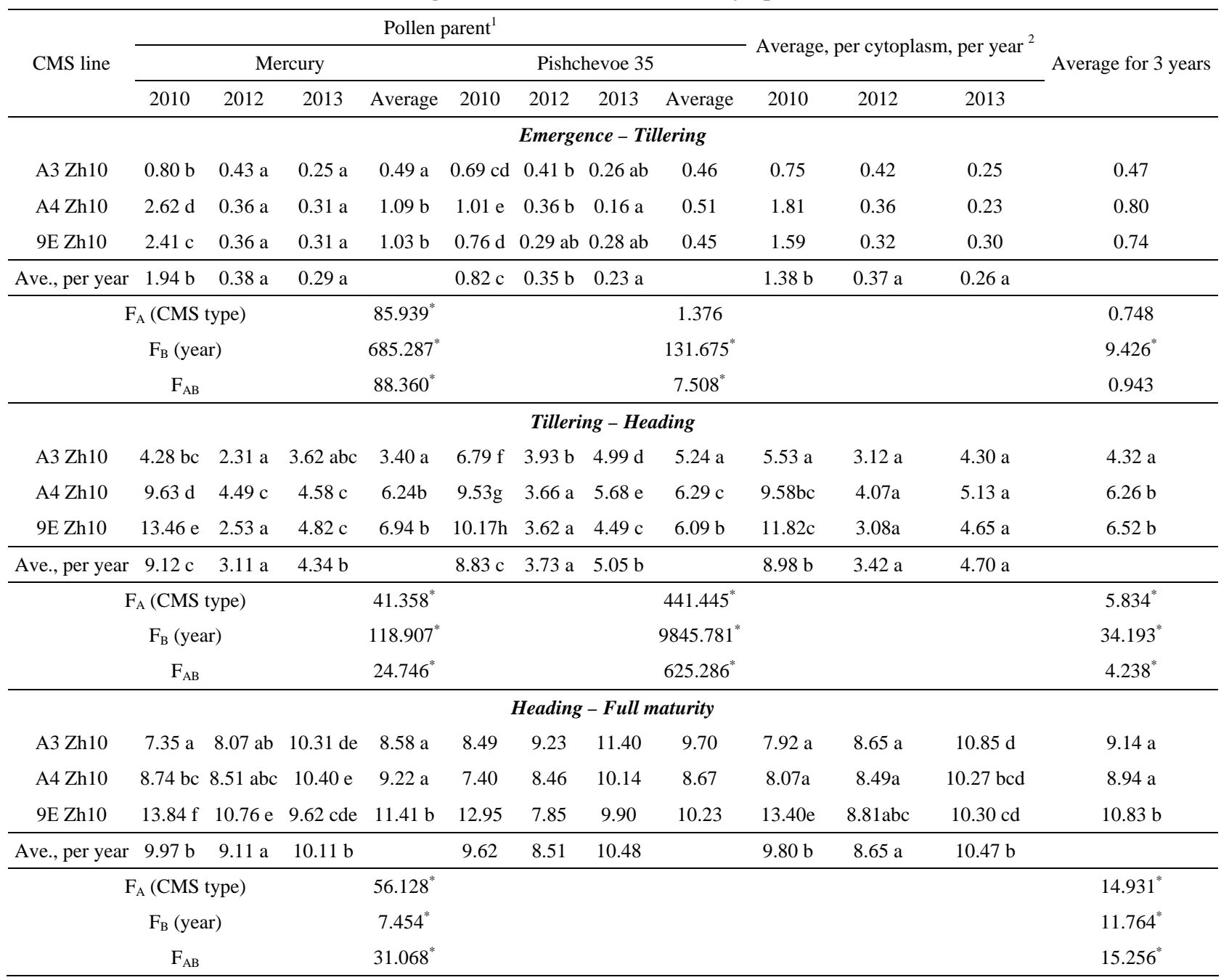

Notes: ${ }^{1}$ data for each hybrid combination, and ${ }^{2}$ for each cytoplasm type, denoted with different letters, differ at $p<0.05$ according to Duncan's Multiple Range Test; ${ }^{*} p<0.05$. 
Table 2. Content of the absolutely dry matter in $F_{1}$ grain sorghum hybrids obtained on the basis of iso-nuclear CMS-lines with P614 nuclear genome in the 9E and M35-1A cytoplasm, 2010-2013, t/ha

\begin{tabular}{|c|c|c|c|c|c|c|c|c|c|c|c|c|}
\hline \multirow{3}{*}{ CMS line } & \multicolumn{8}{|c|}{ Pollen parent ${ }^{1}$} & \multirow{2}{*}{\multicolumn{3}{|c|}{$\begin{array}{c}\text { Average, per cytoplasm, } \\
\text { per year }^{2}\end{array}$}} & \multirow{3}{*}{$\begin{array}{l}\text { Average, for } \\
3 \text { years }\end{array}$} \\
\hline & \multicolumn{4}{|c|}{ Mercury } & \multicolumn{4}{|c|}{ Pishchevoe 35} & & & & \\
\hline & 2010 & 2012 & 2013 & Average & 2010 & 2012 & 2013 & Average & 2010 & 2012 & 2013 & \\
\hline \multicolumn{13}{|c|}{ Emergence - Tillering } \\
\hline 9E P614 & 0.28 & 0.21 & 0.20 & 0.23 & 0.62 & 0.26 & 0.25 & 0.38 & 0.45 & 0.23 & 0.22 & 0.30 \\
\hline M35-1A P614 & 0.44 & 0.22 & 0.19 & 0.29 & 0.52 & 0.30 & 0.17 & 0.33 & 0.48 & 0.26 & 0.18 & 0.31 \\
\hline Average, per year & 0.36 & 0.22 & 0.20 & & 0.57 & 0.28 & 0.22 & & $0.46 \mathrm{~b}$ & $0.25 \mathrm{a}$ & $0.20 \mathrm{a}$ & \\
\hline \multicolumn{5}{|c|}{$\mathrm{F}_{\mathrm{A}}$ (CMS type) } & & & & & & & & 0.004 \\
\hline \multicolumn{5}{|c|}{$\mathrm{F}_{\mathrm{B}}$ (year) } & & & & & & & & $10.140^{*}$ \\
\hline \multicolumn{5}{|c|}{$\mathrm{F}_{\mathrm{AB}}$} & & & & & & & & 0.226 \\
\hline \multicolumn{13}{|c|}{ Tillering - Heading } \\
\hline 9E P614 & $2.38 \mathrm{e}$ & $1.61 \mathrm{~cd}$ & $1.38 \mathrm{~b}$ & $1.79 \mathrm{~b}$ & $3.14 \mathrm{e}$ & $1.89 \mathrm{bc}$ & $2.39 \mathrm{~d}$ & $2.48 \mathrm{~b}$ & 2.76 & 1.75 & 1.88 & $2.13 \mathrm{~b}$ \\
\hline M35-1A P614 & $1.73 \mathrm{~d}$ & $1.01 \mathrm{a}$ & $1.38 \mathrm{~b}$ & $1.38 \mathrm{a}$ & $1.22 \mathrm{a}$ & $2.03 \mathrm{~cd}$ & $1.46 \mathrm{a}$ & $1.57 \mathrm{a}$ & 1.48 & 1.52 & 1.42 & $1.47 \mathrm{a}$ \\
\hline Average, per year & $2.06 \mathrm{~b}$ & $1.31 \mathrm{a}$ & $1.38 \mathrm{a}$ & & 2.18 & 1.96 & 1.93 & & 2.12 & 1.63 & 1.65 & \\
\hline \multicolumn{3}{|c|}{$\mathrm{F}_{\mathrm{A}}$ (CMS type) } & \multicolumn{3}{|c|}{$109.309^{*}$} & \multicolumn{3}{|r|}{$106.901^{*}$} & & & & $7.175^{*}$ \\
\hline \multicolumn{3}{|c|}{$\mathrm{F}_{\mathrm{B}}$ (year) } & \multicolumn{3}{|c|}{$142.809^{*}$} & \multicolumn{3}{|r|}{3.231} & & & & 1.645 \\
\hline \multicolumn{3}{|c|}{$\mathrm{F}_{\mathrm{AB}}$} & \multicolumn{3}{|c|}{$28.121^{*}$} & & & $45.559^{*}$ & & & & 1.684 \\
\hline \multicolumn{13}{|c|}{ Heading - Full maturity } \\
\hline 9E P614 & $3.2 \mathrm{a}$ & $4.38 \mathrm{bc}$ & $3.49 \mathrm{a}$ & 3.71 & 5.43 & 5.09 & 6.35 & $5.62 \mathrm{~b}$ & 4.32 & 4.74 & 4.92 & 4.66 \\
\hline M35-1A P614 & $3.24 \mathrm{a}$ & $3.61 \mathrm{a}$ & $4.70 \mathrm{c}$ & 3.85 & 3.27 & 4.69 & 5.02 & $4.33 \mathrm{a}$ & 3.26 & 4.15 & 4.86 & 4.09 \\
\hline Average, per year & $3.25 \mathrm{a}$ & $4.00 \mathrm{~b}$ & $4.10 \mathrm{~b}$ & & 4.35 & 4.89 & 5.68 & & 3.78 & 4.44 & 4.89 & \\
\hline \multicolumn{3}{|c|}{$\mathrm{F}_{\mathrm{A}}$ (CMS type) } & & 0.762 & & & & $10.720^{*}$ & & & & \\
\hline \multicolumn{3}{|c|}{$F_{B}$ (year) } & \multicolumn{3}{|c|}{$12.175^{*}$} & & & 3.842 & & & & \\
\hline \multicolumn{3}{|c|}{$\mathrm{F}_{\mathrm{AB}}$} & \multicolumn{3}{|c|}{$14.138^{*}$} & & & 1.661 & & & & \\
\hline
\end{tabular}

Notes: ${ }^{1}$ data for each hybrid combination, and ${ }^{2}$ for each cytoplasm type, denoted by different letters, differ at $p<0.05$ according to Duncan’s Multiple Range Test; ${ }^{*} p<0.05$.

Table 3. Manifestation of true heterosis for absolutely dry matter in the $F_{1}$ grain sorghum hybrids in the A3, A4, and 9E sterile cytoplasms

\begin{tabular}{|c|c|c|c|c|c|c|c|c|c|}
\hline \multirow{3}{*}{ Hybrid combination } & \multicolumn{9}{|c|}{ Heterosis for absolutely dry matter content at different stages of ontogenesis, \% } \\
\hline & \multicolumn{3}{|c|}{ emergence - tillering } & \multicolumn{3}{|c|}{ tillering - heading } & \multicolumn{3}{|c|}{ heading - full maturity } \\
\hline & 2010 & 2012 & 2013 & 2010 & 2012 & 2013 & 2010 & 2012 & 2013 \\
\hline A3 Zh $10 \times$ Mercury & 105.13 & 48.28 & -7.14 & 65.25 & 30.51 & 145.58 & 198.78 & 142.34 & 156.23 \\
\hline A4 Zh $10 \times$ Mercury & 413.73 & 28.57 & 20 & 271.81 & 274.17 & 104.47 & 297.27 & 155.56 & 114.43 \\
\hline 9E Zh $10 \times$ Mercury & 760.71 & -18.18 & 183.3 & 419.69 & 74.48 & 157.75 & 333.86 & 177.32 & 93.37 \\
\hline A3 Zh $10 \times$ Pishchevoe 35 & 76.92 & -10.87 & -7.14 & 52.58 & 122.03 & 203.66 & 245.12 & 76.82 & 120.08 \\
\hline A4 Zh $10 \times$ Pishchevoe 35 & 98.04 & -21.74 & -44 & 114.16 & 203.33 & 217.32 & 236.36 & 62.07 & 95.75 \\
\hline 9E Zh $10 \times$ Pishchevoe 35 & 204.00 & -36.96 & 40 & 128.54 & 149.66 & 140.11 & 305.96 & 50.38 & 91.12 \\
\hline 9E P $614 \times$ Mercury & 12 & -19.23 & -4.76 & -8.11 & 103.80 & -3.5 & 117.33 & 31.53 & -12.06 \\
\hline M35-1A P $614 \times$ Mercury & -31.25 & -15.38 & 5.56 & -33.20 & 38.36 & 1.46 & 147.32 & 8.41 & 29.86 \\
\hline 9E P $614 \times$ Pishchevoe 35 & 148.00 & -43.48 & 28.57 & -29.44 & 139.24 & 46.34 & 219.41 & -2.5 & 22.59 \\
\hline M35-1A P $614 \times$ Pishchevoe 35 & -18.75 & -34.78 & -15 & -72.58 & 99.02 & -10.98 & 92.35 & -10.15 & -1.93 \\
\hline
\end{tabular}


In the $\mathrm{F}_{1}$ hybrids with iso-nuclear CMS lines with the P614 nuclear genome in the 9E and M35-1A cytoplasms, on average over 3 years of research, pronounced differences in the ADM content were observed at the "tillering - heading" stage, the $9 \mathrm{E}$ cytoplasm increased its value (2.13 t/ha) in comparison with the cytoplasm M35-1A (1.47 t/ha) (Table 2). This effect was most noticeable in the dry 2010 in the hybrids with both pollen parents. At the "heading - full maturity" stage, significant effect of the cytoplasm type was observed only in hybrids with the Pischevoe 35 paternal parent, the 9E cytoplasm also increased the ADM index (5.62 t/ha versus $4.33 \mathrm{t} / \mathrm{ha}$ in the M35-1A cytoplasm). A significant effect of cytoplasm $\times$ year interaction was observed in hybrids with the Mercury at both stages of ontogenesis.

Comparative analysis of the content of absolutely dry matter in hybrids and parental lines revealed the presence of significant heterosis for this trait, the level of which varied in different seasons. In the extremely drought 2010 season, in the hybrids with the iso-nuclear CMS lines with Zh10 nuclear genome and both paternal parents, Mercury and Pishchevoe 35, the maximum heterosis at all studied stages of ontogenesis was observed in the 9E cytoplasm, while the minimum values - in the A3 cytoplasm (Table 3).

In a humid 2012, the maximum indicators of heterosis at the "tillering - heading" stage were observed in hybrids in the A4 cytoplasm (274\% in the hybrids with Mercury and 203\% in the hybrids with Pishchevoe 35). At the same time, at the stage "heading - full maturity", hybrids differed in the manifestation of heterosis: in hybrids with Mercury, the maximum value was observed in the $9 \mathrm{E}$ cytoplasm (177\%), and the minimum -in the A3 cytoplasm (142\%), while in the hybrids with Pishchevoe 35, the opposite situation took place. These differences may be a consequence of the different duration of ontogenesis in the $\mathrm{F}_{1}$ hybrids Zh10 $\times$ Mercury (more early maturing) and Zh10 $\times$ Pischevoe 35 (late maturing), as a result of which the same stage of ontogenesis proceeded under different hydro-thermal conditions. In 2013, which was characterized by the high HTC (mild growing conditions), the highest values of heterosis at the final stage of ontogenesis, "heading - full maturity", were observed in hybrids in the A3 cytoplasm, and the lowest-in the 9E cytoplasm.

In the $\mathrm{F}_{1}$ hybrids of iso-nuclear CMS lines with the P614 nuclear genome, both pollen parents, Mercury and Pishchevoe 35, gave higher heterosis indices for the ADM at all stages of ontogenesis in the 9E cytoplasm, compared with the M35-1A cytoplasm (Table 3). This difference was observed in each season of investigation.

\section{Discussion}

Genetic effects of cytoplasmic background on the manifestation of many plant traits and functions, including those of great biological and economic importance are well-documented. Maternally inherited disfunction of male generative structures, or cytoplasmic male sterility, resulting from the functioning of mitochondrial CMS-inducing genes is one of the most striking examples of cytoplasmic inheritance [22, 23]. Although the expression of CMS-inducing genes, as a rule, is tissue- and organ-specific, the effects of CMS-inducing cytoplasms can be observed at different stages of plant ontogenesis and affect the manifestation of various plant traits, including those of high agronomic value (for review, see: [11]).

The data, presented above indicate a significant effect of the type of cytoplasm on the content of ADM in sorghum hybrids. The hybrids used in this study were obtained on the basis of iso-nuclear CMS lines differing from each other only in the type of cytoplasm. Therefore, a comparison of such hybrids with each other allows one to reveal in its pure form the presence or absence of the influence of the cytoplasm on a given trait. It was found that the A3 cytoplasm reduced the ADM value at the "tillering - heading" stage, while the 9E cytoplasm contributed to the increase of ADM.

It is noteworthy that significant effects of the cytoplasm type were recorded only under certain environmental conditions, namely, under poor plant water availability conditions (at low HTC values). In the conditions of severely arid 2010, the strongest differences were observed, while in milder conditions of the seasons of 2012 and 2013 these differences were less noticeable, but still statistically significant. At the same time, hybrids with CMS lines in the 9E cytoplasm were characterized by higher ADM indices as compared to hybrids in other types of cytoplasms. Apparently, the 9E cytoplasm contributed to the higher drought resistance of plants, in contrast to the A3 and A4 cytoplasms. These data are consistent with other observations, in which the manifestation of the effect of the cytoplasm on the combining ability of CMS lines of sorghum depended on the hydrothermal conditions of plant growth [24]. A similar dependence of the manifestation of cytoplasmic effects on environmental conditions was found in Pennisetum americanum, where the A4 and A5 cytoplasms exhibited greater tolerance compared to the A1, A2, and A3 cytoplasms [25].

The positive role of the 9E cytoplasm in the selection of heterotic sorghum hybrids was also found in previous studies. It was reported that the 9E cytoplasm increased the leaf width in Sorghum-Sudanese hybrids [26], as well as in the grain sorghum hybrids, where the 9E cytoplasm increased the photosynthetic potential during the period of "heading - full maturity" [27], as well as the intensity of the starting growth and productivity of biomass in the dry seasons [11]. 


\section{Conclusion}

Thus, for the first time, in the grain sorghum hybrids, the effect of the type of sterile cytoplasm on the content of $\mathrm{ADM}$ and on the manifestation of true heterosis for this trait was recorded. The influence of the hydrothermal regime of plant growing and the genotype of parental lines on the manifestation of the cytoplasmic effect was established. It has been shown that under drought conditions, the 9E cytoplasm has a positive effect on the value of ADM at the "tillering - heading" and "heading - full maturity" stages, while A3 cytoplasm under the same conditions reduces this indicator at all stages of plant ontogenesis. The experimental results presented in this study confirm the essential role of the cytoplasm in ensuring plant tolerance to drought stress. These data point on the prospect of study the expression of genes involved in stress response in different types of CMS-inducing cytoplasms of sorghum.

\section{Acknowledgement}

The work was funded in part by the Russian Foundation for Basic Research, grant 19-016-00117.

\section{References}

[1] Tari, I., Laskay, G., Takacs, Z., and Poor, P. (2013). Response of Sorghum to Abiotic Stresses: A Review. Journal of Agronomy and Crop Science, 199(4), 264-274. DOI: 10.1111/jac.12017.

[2] Amelework, B., Shimelis, H., Tongoona, P., and Laing, M. (2015). Physiological Mechanisms of Drought Tolerance in Sorghum, Genetic Basis and Breeding Methods: A Review. African Journal of Agricultural Research, 10(31), 3029-3040. DOI: 10.5897/AJAR2015.9595.

[3] Badigannavar, A., Teme, N., Costa de Oliveira, A., Li, G., Vaksmann, M., Viana, V. A., Ganapathi, T. R., and Sarsu, F. (2018). Physiological, Genetic and Molecular Basis of Drought Resilience in Sorghum [Sorghum bicolor (L.) Moench]. Indian Journal of Plant Physiology, 23(4), 670-688. DOI: 10.1007/s40502-018-0416-2.

[4] Nanaiah, G. K. and Rakshit, S. (2020). Genomic Designing for Climate Smart Sorghum. In Kole, C., Ed., Genomic Designing of Climate-Smart Cereal Crops. Springer Nature, 171-217. DOI: 10.1007/978-3-319-93381-8_5.

[5] Proietti, I., Frazzoli, C., and Mantovani, A. (2015). Exploiting Nutritional Value of Staple Foods in the World's Semi-Arid Areas: Risks, Benefits, Challenges and Opportunities of Sorghum. Healthcare (Basel), 3(2): 172-193. DOI: 10.3390/healthcare3020172.

[6] Premalatha, N., Kumaravadivel, N., and Veerabadhiran, P. (2006). Heterosis and Combining Ability for Grain Yield and its Components in Sorghum [Sorghum bicolor (L.) Moench]. Indian Journal of Genetics, 66(2), 123-126.

[7] Kovtunova, N. A., Volodin, A. B., and Kovtunov, V. V. (2017). Heterosis in Breeding of Sweet Sorghum. Grain Economy of Russia, 49(1), 11-17.

[8] Volodin, A. B., Donets, I. A., Golub, A. S., Chukhlebova, N. S., and Kapustin, A. S. (2018). Use of Cytoplasmic Male Sterility in The Selection of Sorghum Cultures. Research Journal of Pharmaceutical, Biological and Chemical Sciences, 9(6), 1562-1565.

[9] Pring, D. R., Tang, H. V., and Schertz, K. F. (1995). Cytoplasmic Male Sterility and Organelle DNAs of Sorghum. In: Levings, C. S., III, and Vasil, I. K. (Eds.), Molecular Biology of Plant Mitochondria, Springer, Netherlands, 461-495. DOI: 10.1007/978-94-011-0163-9_14.

[10] Reddy, B. V. S., Ramesh, S., and Ortiz, R. (2005). Genetic and Cytoplasmic-Nuclear Male Sterility in Sorghum. Plant Breeding Rewiews, 25, 139-169. DOI: 10.1002/9780470650301.ch6.

[11] Elkonin, L. A., Kibalnik, O. P., Zavalishina, A. N., Gerashchenkov, G. A., and Rozhnova, N. A. (2018). Genetic Functions of Cytoplasm in Plants with Special Emphasis on Sorghum. In: Dejesus, C. and Trask, L. (Eds.), Chloroplasts and Cytoplasm. Structure and Functions, Nova Science Publ., New-York, 97-154.

[12] Fujii, S., Yamada, M., Fujita, M., Itabashi, E., Hamada, K., Yano, K., Kurata, N., and Toriyama, K. (2010). Cytoplasmic-Nuclear Genomic Barriers in Rice Pollen Development Revealed by Comparison of Global Gene Expression Profiles among Five Independent Cytoplasmic Male Sterile Lines. Plant Cell Physiology, 51, 610-620. DOI: 10.1093/pcp/pcq026.

[13] Li, C.-R., Liang, D.-D., Li, J., Duan, Y. B., Li, H., Yang, Y.-C., Qin, R.-Y., Li, L., Wei, P.-C., and Yang, J.-B. (2013). Unravelling Mitochondrial Retrograde Regulation in the Abiotic Stress Induction of Rice ALTERNATIVE OXIDASE 1 Genes. Plant, Cell and Environ, 36, 775-788. DOI: 10.1111/pce.12013.

[14] Ng, S., De Clercq, I., Van Aken, O., Law, S. R., Ivanova, A., Willems, P., Giraud, E., Van Breusegem, F., and Whelan, J. (2014). Anterograde and Retrograde Regulation of Nuclear Genes Encoding Mitochondrial Proteins During Growth, Development, and Stress. Molecular Plant, 7, 1075-1093. DOI: 10.1093/mp/ssu037.

[15] Liberator, K. L., Dukowic-Schulze, S., Miller, M. E., Chen, C., and Kianian, S. F. (2016). The Role of Mitochondria in Plant Development and Stress Tolerance. Free Radical Biology and Medicine, 100, 238-256. DOI: 10.1016/j.freeradbiomed.2016.03.033.

[16] Jenkins, B. M., Baxter, L. L., Miles, T. R. Jr., and Miles, T. R. (1998). Combustion Properties of Biomass. Fuel Processing Technology, 54, 17-46. DOI: 10.1016/S0378-3820(97)00059-3.

[17] Perazzo, A. F., Carvalho, G. G. P., Santos, E. M., Bezerra, H. F. C., Silva, T. C., Pereira, G. A., Ramos, R. C. S., and Rodrigues, J. A. S. (2017). Agronomic Evaluation of Sorghum Hybrids for Silage Production Cultivated in Semi-Arid Conditions. Fron- 
tiers in Plant Science, 8, 1088. DOI: 10.3389/fpls.2017.01088.

[18] Elkonin, L. A., Kozhemyakin, V. V., and Ishin, A. G. (1997). The Use of New CMS-Inducing Cytoplasms to Create Early Maturing Lines of Sorghum with Male Sterility. Russian Agricultural Sciences, 2, 7-9.

[19] Dospekhov, B. A. (2014). Methodology of Field Trial (with Fundamentals of Statistical Processing of Research Results), Alyans, Moscow.

[20] Guzhov, Yu. L., Fuks, A., and Valichek, P. (2003). Selection and Seed Production of Cultivated Plants. 3rd Edition, Mir, Moscow.

[21] Cherenkova, E. A. and Zolotokrylin, A. N. (2016). On the Comparability of Some Quantitative Drought Indices. Fundamental and Applied Climatology, 2, 79-94. DOI: 10.21513/2410-8758-2016-2-79-94.

[22] Bohra, A., Jha, U. C., Adhimoolam, P., Bisht, D., and Singh, N. P. (2016). Cytoplasmic Male Sterility (CMS) in Hybrid Breeding in Field Crops. Plant Cell Repts., 35, 967-993. DOI: 10.1007/s00299-016-1949-3.

[23] Horn, R., Gupta, K. J., and Colombo, N. (2014). Mitochondrion Role in Molecular Basis of Cytoplasmic Male Sterility. Mitochondrion, 19, 198-205. DOI: 10.1016/j.mito.2014.04.004.

[24] Kibalnik, O. P. and Elkonin, L. A. (2020). Influence of Different Types of Sterile Cytoplasms (A3, A4, 9E) on the Combining Ability of CMS Lines of Sorghum. Vavilov Journal of Genetics and Breeding, 24(6), 549-556. DOI: 10.18699/VJ20.648.

[25] Chandra-Shekara, A. C., Prasanna, B. M., Singh B. B., Unnikrishnan, K. V., and Seetharam, A. (2007). Effect of Cytoplasm and Cytoplasm-Nuclear Interaction on Combining Ability and Heterosis for Agronomic Traits in Pearl Millet \{Pennisetum glaucum (L) Br. R\}. Euphytica, 153, 15-26. DOI: 10.1007/s10681-006-9194-4.

[26] Kibal'nik, O. P. and El'konin, L. A. (2012). Effect of Type of Sterile Cytoplasm on Manifestation of Economically Valuable Traits in Sorghum-Sudangrass Hybrids. Russ. Agricult. Sci., 38, 22-25. DOI: 10.3103/S1068367412010107.

[27] Bychkova, V. V. and Elkonin, L. A. (2016). The Effect of the Type of Sterile Cytoplasm on the Photosynthetic Parameters of the Grain Sorghum Hybrids. Grain Economy of Russia, 4, 5-8. 